\title{
Can Individual Venture Capital Promote Regional Technological Innova- tion?-Empirical Test Based on Chinese Provincial Data in 2016
}

\author{
Ning Sun ${ }^{1, a}$ \\ ${ }^{1}$ School of Economics and Management, Beijing Jiaotong University, Beijing, China \\ asunning_18@163.com \\ ${ }^{*}$ Ning Sun
}

Keywords: Venture Investor, Regional Technological Innovation, Spatial Correlation.

\begin{abstract}
Based on the sectional data of 28 provinces in China in 2016, this paper analyzes the dynamic relationship between individual venture capital and regional technological innovation by using non-spatial linear regression model and relevant spatial model. The research shows that there is a significant positive correlation between individual venture capital and technological innovation under the non-spatial model, that is, individual venture capital can effectively promote the development of technological innovation. However, after the introduction of spatial variables, the spatial autoregression coefficient and spatial error coefficient of the model are not very significant, so the data should be further improved and further studies should be conducted.
\end{abstract}

\section{Introduction}

Innovation is the primary driving force. At present, the level of the high and new technology has become the key factor of the comprehensive strength competition of in the world. However, technological innovation is a long process, which is the process of enterprises applying new knowledge and technology to improve product quality, develop new products and provide new services in order to occupy the market and realize the market value. During this period, a large amount of capital investment will be required, and venture capital, a new form of financing, has begun to enter people's field of vision.

At present, researches on venture capital and technological innovation are mainly carried out from three perspectives: countries, industries and enterprises. At the national level, Tykvova (2001) found a positive correlation between venture capital and patent application volume in Germany. In terms of industry, Burns et al. (2009) found that venture capital plays a significant positive role in developing technological innovation in the field of life sciences and enhancing market competitiveness of enterprises. From the perspective of enterprises, Kortumand Lerner (2000) found through empirical research that among the listed companies in the United States, the promotion effect of venture capital on enterprise patent output was 3.1 times that of the intensity of R\&D investment.

A large number of scholars have conducted in-depth research on the relationship between venture capital and technological innovation and have achieved a lot of results. However, considering the research at the regional level is less, therefore, this paper will introduce a spatial analysis model to study the individual risk investment behavior to the region innovation, and provide a possible way to study the relationship between venture capital and innovation.

\section{Definition and Literature Review}

\subsection{Venture Investor}

Venture capital (VC) is a type of private equity, a form of financing that is provided by firms or funds to small, early-stage, emerging firms that are deemed to have high growth potential, or which have demonstrated high growth.

Venture Investor. Duan Xinsheng et al. (2017) defined it as both an investor and an operator, that is, a person who can be regarded as a venture enterprise that accepts venture capital, raises and manages venture capital in an organized way, seeks and selects investment projects, invests, supervises 
and assists venture enterprises. Gong Zhe et al. (2012) believe that venture capitalists not only provide capital for venture enterprises, but also provide professional expertise and management experience.

\subsection{Technological Innovation}

Freeman (1973) believes that technological innovation is the whole process of technology and commercialization, which leads to the market realization of new products and the commercial application of new technology processes and equipment. Technological innovation plays an important role in promoting economic growth and enhancing national competitiveness.

The current empirical research is mainly to study which specific factors can promote economic growth through improving technological innovation ability. Bravo Ortega and Marin (2011) shown that for every $10 \%$ increase in per capita $R \& D$, an economy's long-term productivity increases by $1.6 \%$ on average. Lu Fangyuan et al. (2011) found that R\&D investment has a significant role in promoting economic growth.

\subsection{Venture Investor and Innovation}

There is not much literature on the relationship between venture capitalists and innovation. Kolympiris and Kalaitzandonakes (2013) found that venture capital has greatly contributed to the increase in patent rates. Park, Tzabbar (2016) studied how the interdependence between venture capitalists and corporate CEOs affects the innovation of new firms at different stages of development. Based on a sample of 482 US biotech companies, venture capital firms were encouraged to encourage their investors to pursue risky and novel innovations in the early stage of a new venture, but discourage them from doing so in the late stage of the venture.

\section{Research Design}

\subsection{Indicator Selection and Data Source}

In view of the availability of data, 28 provincial-level regions in China in 2016 (excluding Jiangxi, Guangxi, Tibet, Hong Kong, Macao and Taiwan) were selected as sample sources. The calculation data comes from China science and technology statistical yearbook 2017; China venture capital development report 2017; China statistical yearbook of science and technology 2017 and China labor statistics yearbook.

There are three kinds of index type, innovative output indicator, innovation input indicator and regional attribute indicator. In this paper, we use patent application quantity $(P)$ to measure innovation output, and individual venture capital $\left(V_{P e r s}\right), \mathrm{R} \& \mathrm{D}$ capital $(R D C)$ and $\mathrm{R} \& \mathrm{D}$ personnel $(R D P)$ to measure innovation input. The attribute of a region mainly refers to the level of human capital $(H R)$, that is, the average number of years of education of the working population in the region.

\subsection{Model Method}

\subsubsection{Basic Model}

Griliches first proposed an analytical framework for analyzing regional knowledge production and spillovers. Its knowledge production function is:

$$
Y=\mathrm{F}(X, K, u)
$$

Where, $Y$ is output, $X$ is normal production input variables, such as capital, labor, land, etc. $K$ is the degree of technological progress, and $u$ is the random error term.

On this basis, the regression model is constructed as follows:

$$
\ln P=\alpha+\beta_{1} \ln V C_{\text {Pers }}+\beta_{2} \ln R D C+\beta_{3} \ln R D P+\beta_{4} H R+\varepsilon_{i t}
$$

Where, $\alpha$ represents truncation term, $\beta_{i}$ represents the estimation coefficient of each variable, and $\varepsilon_{i t}$ represents the error term.

\subsubsection{Estimation Methods}

A lot of economic data involves a certain spatial location, where everything is related to else, but things that are closer are more relevant than things that are farther away. With the development of 
spatial econometrics, the interaction between different regions has attracted more scholars' attention. Anselin is the first scholar who combines knowledge production function with spatial econometric model to analyze regional technological innovation. Correlation models include: Spatial Autoregression Model (SAR), Spatial Error Model (SEM) and Spatial Durbin Model (SDM).

\section{Empirical Analysis}

\subsection{Variable Correlation Coefficients and Descriptive Statistics}

The correlation coefficients and descriptive statistics of the main variables are shown in Table 1. Among them, the four variables of personal venture capital, R\&D capital, R\&D personnel and human capital are all proportional to the technology innovation index, and most of them are tested at the $1 \%$ significance level, indicating that these four variables are for regional technological innovation. There is a significant impact. According to the descriptive statistics, the average value of the personal venture capital index is 5.55 and the variance is 2.91 , indicating that there is an imbalance in the spatial distribution of China's venture capital activities.

Table 1. Correlation Coefficient and Descriptive Statistics of Main Variables

\begin{tabular}{cccccc}
\hline Variable & $\ln P$ & $\ln V C_{\text {Pers }}$ & $\ln R D C$ & $\ln R D P$ & $H R$ \\
\hline $\ln P$ & & $0.814^{* * *}$ & $0.937^{* * *}$ & $0.958^{* * *}$ & $0.364^{*}$ \\
$\ln V C_{\text {Pers }}$ & $0.769^{* * *}$ & & $0.782^{* * *}$ & $0.792^{* * *}$ & $0.321^{*}$ \\
$\ln R D C$ & $0.969^{* * *}$ & $0.701^{* * *}$ & & $0.985^{* * *}$ & $0.464^{* *}$ \\
$\ln R D P$ & $0.841^{* * *}$ & $0.655^{* * *}$ & $0.821^{* * *}$ & & $0.421^{* *}$ \\
$H R$ & $0.389^{* *}$ & $0.334^{*}$ & $0.488^{* * *}$ & $0.381^{* *}$ & \\
Observation & 28 & 28 & 28 & 28 & 28 \\
Mean & 10.17 & 5.55 & 14.85 & 20.23 & 11.58 \\
Variance & 1.39 & 2.91 & 1.34 & 20.15 & 1.03 \\
Note: *** 、** and * respectively represent significant at levels of $1 \%, 5 \%$ and $10 \%$. &
\end{tabular}

\subsection{Spatial Correlation Test}

In order to carry out spatial correlation test, Moran's I and Geary's C of regional technological progress in China were calculated and double-tailed test was carried out, as shown in table 2. The Moran index is positive and significant at the $1 \%$ level, indicating that regional technological innovation has significant spatial correlation, that is, different regions influence each other.

Table 2. Global Space Autocorrelation Test Results

\begin{tabular}{cccc}
\hline Statistics & Index & Z Value & P Value \\
\hline Moran's I & 0.308 & 2.858 & 0.004 \\
Geary's C & 0.517 & -2.946 & 0.003 \\
\hline
\end{tabular}

\subsection{Spatial Measurement Model and Result Analysis}

This paper uses spatial autoregressive model (SAR) and spatial error model (SEM) to study and analyze.

\subsubsection{SAR Model}

The SAR model estimation results are shown in table 3. Although the indicators have basically passed the test and are significant, the spatial autoregression coefficient (Rho) is estimated to be -0.001 , which fails the test and shows no significant performance. Therefore, the conclusion that spatial autoregression effect exists cannot be obtained from the existing data. 
Table 3. SAR Model Results

\begin{tabular}{cccc}
\hline $\ln P$ & Coefficient & Z Value & P Value \\
\hline $\ln V C_{P e r s}$ & 0.737 & 2.97 & 0.003 \\
$\ln R D C$ & 0.875 & 10.41 & 0.000 \\
$\ln R D P$ & 0.006 & 1.43 & 0.154 \\
$H R$ & -0.152 & -2.5 & 0.013 \\
Constant & -1.551 & -1.62 & 0.106 \\
Rho & -0.001 & -0.34 & 0.736 \\
\hline
\end{tabular}

\subsubsection{SEM Model}

The estimation result of SEM model is similar to that of spatial autoregression model. The estimated value of spatial autoregression coefficient (Lamda) of error term is -0.007 , which is not significant and needs further verification.

\section{Conclusions}

From the non-spatial linear regression model, it can be seen that there is a positive correlation between personal risk investment behavior and technological innovation, and the adjusted $\mathrm{R}^{2}$ coefficient reaches $96.06 \%$, indicating that the model can better simulate the relationship between individual venture capital and technological innovation. Relationships, that is, personal risk investment behavior can promote technological innovation.

In terms of space research, spatial autocorrelation and spatial error of spatial econometric model are not significant, indicating that under the current sample, the promotion of technological innovation by individual venture capital is not obvious at the regional level. Due to data limitations, further research is needed. Gather more years of data and delve into other spatial models to see if you can produce different results.

\section{References}

[1] TYKVOVA T. Venture Capital in German and Its Impaction Innovation [EB/OL].(2001-0313)[2011-09-20].http://ideas.repec.org/p/dep/ZZZZZZ/l.html.

[2] Burns Lawton R, Housman Michael G, Robinson Charles A Market Entry and Exit by Biotech and Device Companies Funded by Venture Capital[J].Health Affairs,2009,28(1):76-86.

[3] Kortum, S. and Josh Lemer. Assessing the Contribution of Venture Capital to Innovation [J].Rand Journal of Economics,2000(31):674-692.

[4] Duan Xinsheng and Lin Dan, Judging the "Irrational" Investment of Venture Capitalists from the Shared Bicycle Financing Situation[J]. Friends of Accounting, 2017(24):7-12.

[5] Gong Zhe, Stage Characteristics of Risk Investment and Risk Management Strategy, Technology Information, 2012(29):190-194.

[6] BRAVO-ORTEGA C, MARíN A G. R\&D and Productivity: A Two Way Avenue? [J].World Development,2011,39(7):1090-1107.

[7] Lu Fangyuan and Jin Dandan, An Empirical Analysis on the Effect of R\&D Input to Economic Growth Based on Panel Data, Chinese Industrial Economy, 2011(3):67-67.

[8] Christos Kolympiris, Nicholas Kalaitzandonakes. Geographic Scope of Proximity Effects Among Small Life Sciences Firms. Small Business Economics, 2013, Vol.40 (4), pp.1059-1086.

[9] Park Haemin Dennis, Tzabbar Daniel. Venture Capital, CEOs' Sources of Power, and Innovation Novelty at Different Life Stages of a New Venture. Organization Science, 2016,Vol.27,Issue2,p336-353. 